\title{
Carbon isotopic analyses of microdiamonds
}

Kinny, P.D. ${ }^{1}$, Trautman, R.L. ${ }^{2}$, Griffin, B.J. ${ }^{3}$, and Harte, B. ${ }^{4}$

1. School of Applied Geology, Curtin University of Technology, Perth 6001, Australia

2. Department of Geology and Geophysics, University of Western Australia, Perth 6907, Australia

3. Centre for Microscopy and Microanalysis, University of Western Australia, Perth 6907, Australia

4. Department of Geology and Geophysics, University of Edinburgh, Edinburgh EH9 3JW, United Kingdom

\section{Introduction}

130 microdiamonds $<0.5 \mathrm{~mm}$ diameter were selected from 17 different kimberlitic diatremes around the world for in situ ${ }^{13} \mathrm{C} /{ }^{12} \mathrm{C}$ measurements by ion probe as part of a broader study of their morphological, optical and chemical characteristics (Trautman et al, 1997; this volume).

\section{Analytical methods}

Each microdiamond was sectioned, polished and analysed by cathodoluminescence and FTIR spectrometric methods prior to $\mathrm{C}$ isotopic study. In preparation for $\mathrm{C}$ isotopic analysis, the stones were pressed into a substrate of soft indium metal filling recessed mounts made of stainless steel or aluminium, and gold-coated. In each mount, a plate of a synthetic diamond standard 'syn- $\mathrm{A}^{\text {' }}$ was placed alongside the unknowns. ${ }^{13} \mathrm{C} /{ }^{12} \mathrm{C}$ analyses were done using the Edinburgh CAMECA ims-4f ion probe, following the method developed for large diamonds by Harte and Otter (1992). A 0.5nA primary $\mathrm{Cs}^{+}$beam was employed, sputtering $\mathrm{C}^{-}$ions from a $10 \mu \mathrm{m}$ triangular-shaped area on the cut surface. Typical count-rates for ${ }^{12} \mathrm{C}^{-}$ and ${ }^{13} \mathrm{C}^{-}$of $10^{6}$ and $10^{4}$ counts per second, respectively, were obtained from unknowns and standards alike. A single analysis constituted a one second count on ${ }^{12} \mathrm{C}^{-}$ followed by a six second count on ${ }^{13} \mathrm{C}^{-}$, repeated 50 times. A deadtime correction of 13.5 ns was applied to the raw counts, and a mean ${ }^{13} \mathrm{C} /{ }^{12} \mathrm{C}$ ratio was calculated for each data set. This ratio was then normalized for instrumental isotopic mass fractionation, based on the data obtained for the syn-A standard and its known composition (Fig.1), then converted to $\delta^{13} \mathrm{C}$ notation, which represents permil deviation from the ${ }^{13} \mathrm{C} /{ }^{12} \mathrm{C}$ ratio of the international PDB standard. Estimated uncertainties on individual analyses range from \pm 1.2 to $1.8 \%$.

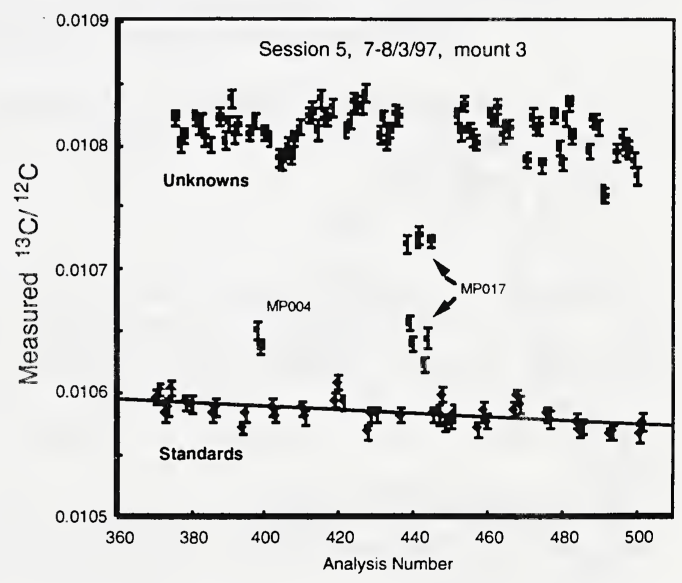

Figure 1. A subset of the raw data. The sloping trend in the standard analyses represents increased mass fractionation over time, due to changing counting efficiency of the electron multiplier detector with use. ${ }^{13} \mathrm{C} /{ }^{12} \mathrm{C}$ ratios of unknowns were corrected by ratioing to an interpolated value for the standard at the time of analysis of each unknown, given that the syn-A standard has a mean $\delta^{13} \mathrm{C}_{\mathrm{PDB}}$ of -23.924 .

\section{Results}

Duplicate ${ }^{13} \mathrm{C} /{ }^{12} \mathrm{C}$ measurements (on adjacent probe spots) were performed on almost every stone analysed, thereby providing an internal check on reproducibility. Additional points were analysed on stones which showed striking CL zonation, in order to test for possible isotopic variations among and between zones, and from core to rim. Up to eight spots were analysed on a few stones in which significant isotopic heterogeneity was found. However, most stones showed no significant variation in ${ }^{13} \mathrm{C} /{ }^{12} \mathrm{C}$ beyond analytical uncertainty, regardless of whether zoned or homogeneous in CL. In fact, the reproducibility of duplicate analyses of the natural unknowns was in most cases superior to that of successive analyses of the syn-A synthetic diamond standard, implying that the standard is less homogeneous than most natural targets and ought to be pensioned off. 
The most dramatic case of isotopic heterogeneity within a single microdiamond was found in a stone from $M$ pipe, Brazil, in which the CL image revealed a curved boundary transecting growth laminae. Four analytical sites on one side of this boundary yielded a mean value of -18 , all within error, whereas four sites on the other side were $7 \%$ o heavier at -11 , again all within error (Fig.2). A number of other, less dramatic examples of heterogeneity coupled to CL zonation were observed, including two stones from the Sytykanskaya kimberlite, Siberia, in which central zones were up to 3\%o lighter than the corresponding overgrowths (Fig.2). (Variations less than approximately $1.5 \%$ are too small to be discerned by this technique at the current level of precision).

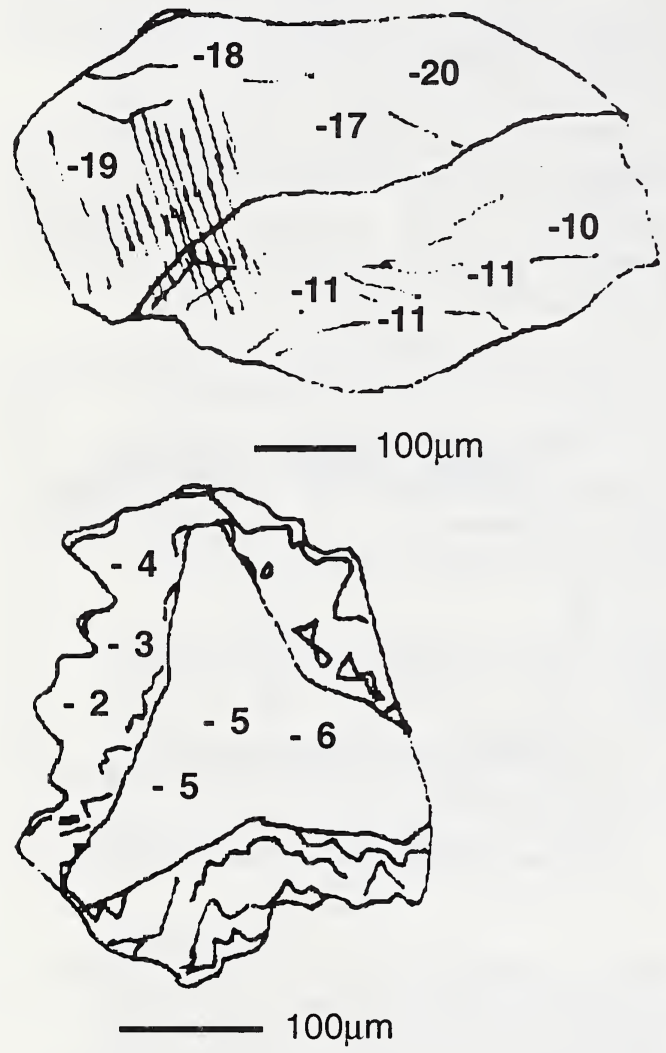

Figure 2. Sketches of sectioned microdiamonds that were found to be isotopically heterogeneous, showing $\delta^{13} \mathrm{C}$ values determined by ion-probe in relation to structures seen by cathodoluminescence. Top: MP017, a patchily zoned dodecahedroid stone from $\mathrm{M}$ pipe, Brazil; Bottom: SY140, an octahedral stone from the Sytykanskaya kimberlite, Siberia, with a cubic growth form in the core and a roughlaid octahedral overgrowth.

Figure 3 is a compilation of all of the $\delta^{13} \mathrm{C}$ data. In broad terms, it shows the familiar skewed distribution of macro-diamond compilations (e.g. Deines, 1980), featuring a prominent peak in the range -2 to -5 , a steep cutoff at approximately zero permil, and a few highly negative values. The total range in measured compositions was from 0 to -21 .
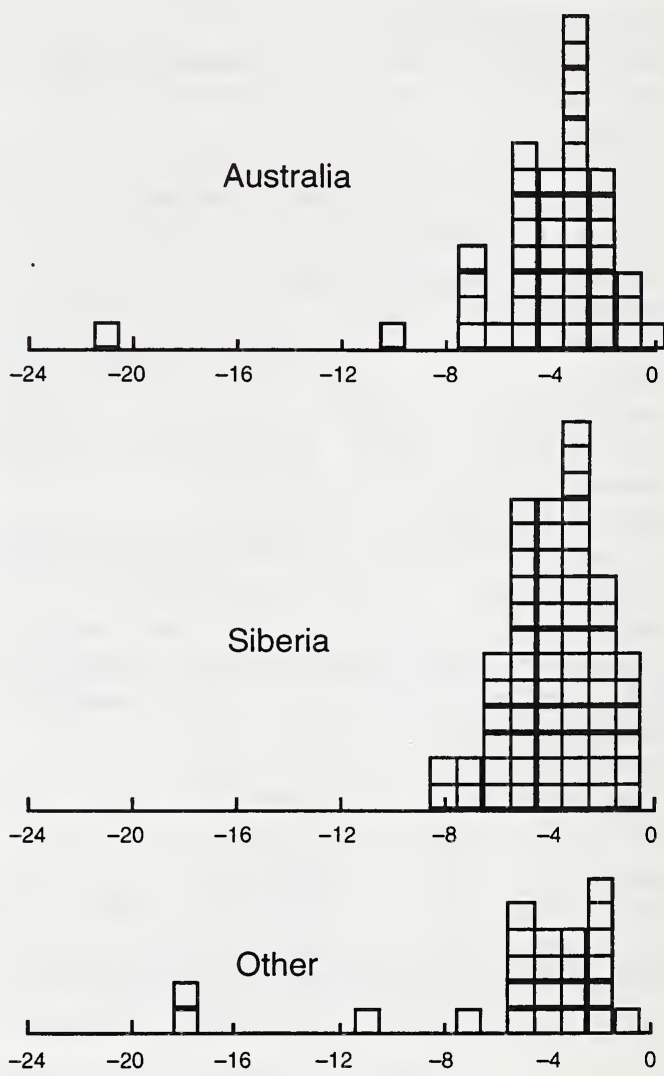

Figure 3. Histograms of mean $\delta^{13} \mathrm{C}$ for each analysed microdiamond (or each zone where a significant difference between zones was found), grouped on a regional basis. Australian localities: Argyle, Aries, Coanjula, Ellendale, Excalibur, Emu-2, Jewill-2, Walgidee Hills; Siberian localities: Aikhal, Mir, Sputnik, Sytykanskaya, Udachnaya, Yulibeynaya; Others: Roberts Victor (South Africa), M pipe (Brazil), Suomi (Finland). 
Comparisons between data sets from individual localities, however, reveal that some systematic differences may exist in the isotopic compositions of micro- and macro-diamond suites in some areas. Our data for ten microdiamonds from the Argyle lamproite in Western Australia, for example, range from -1 to -7 . In contrast, large diamond populations from Argyle peak at about $-12 \%$ (Jaques et al, 1989) with an overall range from 0 to -16 . The microdiamonds from Argyle, therefore, appear to represent either a separate paragenesis to the accompanying macrodiamonds or alternatively a subset of the main population. At other localities where large diamond data are available for comparison, e.g. Roberts Victor, Mir, the microdiamond data are more consistent with the published isotopic distribution patterns for coexisting macrodiamonds.

\section{Conclusions}

Microdiamonds are small diamonds. The overall distribution of carbon isotopic compositions found among microdiamond suites mirrors that of large diamonds. Together with the observations on growth structures and nitrogen aggregation states made by CL imaging and FT-IR spectroscopy (Trautman et al, this volume), this is consistent with the hypothesis that all diamonds of kimberlitic derivation share common origins, irrespective of whether they are the products of a single environment of growth or, more likely, multiple environments and growth stages.

Individual localities have their own unique carbon isotopic distribution patterns in diamonds (e.g. Galimov, 1991). In most instances the distribution patterns obtained from microdiamonds in a single diatreme are very similar to those of their larger cousins, (bearing in mind that the microdiamond data sets from individual localities are small). Argyle, however, appears to be an exception.

Despite its lower precision in relation to other measurement techniques, the superior spatial resolution of ion-probe ${ }^{13} \mathrm{C} /{ }^{12} \mathrm{C}$ analyses has proven useful in being able to detect small-scale isotopic heterogeneities up to $7 \%$ within single crystals.

\section{References}

Deines, P., 1980, The carbon isotopic composition of diamonds: relationship to diamond shape, color, occurrence and vapor composition: Geochim. Cosmochim. Acta, 44, p. 943-961.

Galimov, E.M., 1991, Isotope fractionation related to kimberlite magmatism and diamond formation: Geochim. Cosmochim. Acta, 55, p. 1697-1708.

Harte, B., and Otter, M., 1992, Carbon isotope measurements on diamonds: Chem. Geol. (Isotope Geoscience), 101, p. 177-183.

Jaques, A.L., Hall, A.E., Sheraton, J.W., Smith, C.B., Sun, S.-S., Drew, R.M., Foudoulis, C., and Ellingsen, K., 1989, Composition of crystalline inclusions and C-isotopic composition of Argyle and Ellendale diamonds: In: (J. Ross, ed) Kimberlites and Related Rocks, (Geol. Soc. Aust. Spec. Pub. 14), Vol. 2, 1029-1041.

Trautman, R.L., Griffin, B.J., and Bulanova, G.P., 1997, Growth features and nitrogen aggregation properties of microdiamonds derived from kimberlitic diatremes: This volume.

Trautman, R.L., Griffin, B.J., Taylor, W.R., Spetsius, Z.V., Smith, C.B., and Lee, D.C., 1997, A comparison of the microdiamonds from kimberlite and lamproite of Yakutia and Australia: Proc. 6th Int. Kimberlite Conf., Vol. 2, Russian Geol. and Geophys., 38, 341-355. 